\title{
Expanded use of medical imaging technologies poses challenges
}

Published at www.cmaj.ca on July 21

$\mathrm{T}$ he Canadian health care system faces paralysis unless it improves access to medical imaging, warns the head of the nation's largest medical imaging department.

"Every single specialty has a major need for medical imaging," says Dr. Patrice Bret, chief of medical imaging at the University Health Network in Toronto, Ontario. "So what we see happening is that medical imaging becomes the central core of every health care facility, particularly the large ones. And I don't think the government has grasped that. They still see it as an added service and see medicine or surgery or emergency as the core. They don't realize that these clinical departments or programs are completely paralyzed when imaging is not both available and up to standard."

The chief executive officers of hospitals are struggling to adapt to the critical function that technologies such as single photon emission computed tomography, positron emission tomography (PET) and magnetic resonance imaging (MRI) have on the delivery of health care, he adds, arguing that there's a desperate need to significantly bolster the number of imaging machines in Canada.

"Every week we have more valid MRI requests than we can perform. So guess what? Every week our waiting list gets worse. We run our MRI 24/7. We have become experts in productivity to get the most out of the machine. So if you have the highest productivity, you work your machine 24/7, you control the appropriateness. There's not much more you can do. And if you have a growing waiting list, it is a reasonably good indicator that you don't have enough machines."

That's compounded by the fact that demand is growing for medical images

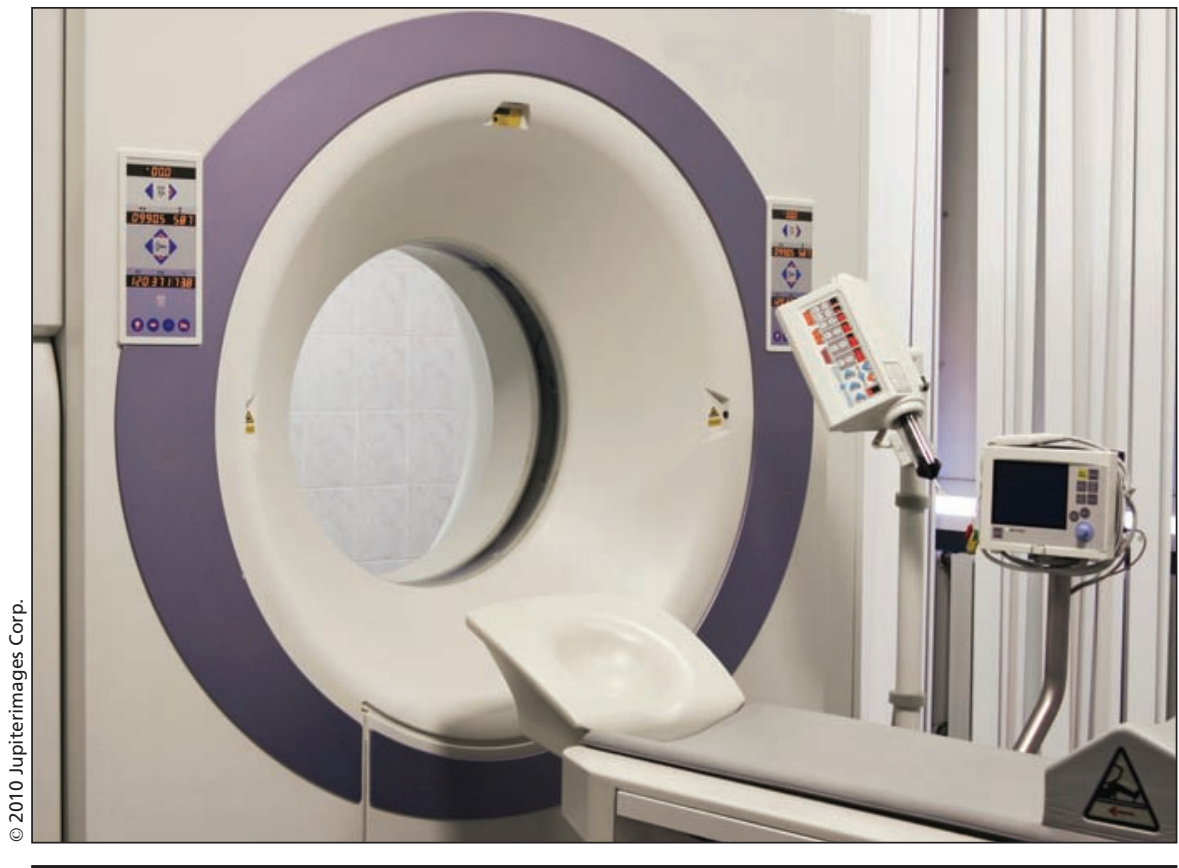

There's a desperate need to significantly bolster the number of imaging machines in Canada, say medical imaging experts.

for conditions other than cataracts, knee injuries and cancer, he adds.

There's no question that imaging is one of the fastest growing sectors of health care, says Dr. Rob Beanlands, director of the National Cardiac PET Centre, chief of cardiac imaging and director of the molecular function and imaging program at the University of Ottawa Heart Institute in Ontario.

But it's debatable whether the technologies are being used on the right people, at the right time and for the right reasons, he says. "We just don't have markers or measures to know if we are using them appropriately. ... But we need to do better comparative effectiveness. What is the right test in that situation, and does that test impact patient outcome, quality of life and/or cost? We don't have enough of that type of research in imaging."

Beanlands also argues that physicians need to more carefully weigh the value of diagnostic tests. "Does the test have added value that will impact management decisions to change outcomes? We need to think about that more consciously. Health care providers combined with payers, being the government, need to work together to find how we better use the resources appropriately" or ultimately, "we'll outstrip our resources."

The institute is now undertaking a study comparing MRI and PET to other standard imaging modalities in ischemic forms of heart failure, in hopes of determining the proper place for such technologies in routine patient care.

But Bret argues the bigger problem is access to those modalities. "It doesn't really matter that you have the good quality if you cannot access it. That's what kills the system."

Access varies widely across Canada, he adds. "If you go to Yellowknife, you won't have the same studies as if you go to downtown Toronto. Although the 
principles of health care are universal, the application of it is very heterogeneous just by the fact of geography. The second aspect of that is that we have a federal health care system but we have a provincial implementation so there is a huge variety in the implementation of medical imaging across the provinces."

Until October 2009, for example, PET was not a reimbursed examination in Ontario, but was covered in most of the other provinces, Bret says. "If you do an ultrasound in Quebec outside of the hospital, it is not a covered test. But if you do it in Ontario, it is publicly funded.

The national variations are a function of provincial jurisdiction over health care, Health Canada spokeswoman Christelle Legault states in an email. "Health Canada has encouraged innovations in access to and the appropriate use of diagnostic imaging, for example, by supporting the Canadian Association of Radiologists in implementing guidelines for diagnostic imaging that will help ensure patients receive the right tests at the right time."

Beanlands says the challenges will only be greater as new imaging modalities emerge. "There is a lot of investment in research into looking at new types of imaging modalities. That's contrasted against our inability to be $100 \%$ certain how to apply the ones that are already out there." - Becky Rynor, Ottawa, Ont.

DOI:10.1503/cmaj.109-3294 